\title{
Improved phyllite packing of CBR value influence factor analysis
}

\author{
Fengjie Zhu ${ }^{a}$, Xuesong Mao ${ }^{\mathbf{b}}$, Wenlin $\mathrm{Li}^{\mathrm{c}}$, Haining Zhang ${ }^{\mathrm{d}}$ \\ School of highway, Chang'an University, Xi'an 710064, China \\ a494712117@qq.com, bxuesongxian@aliyun.com, chd_wenlin@163.com, dshuimumu0808@163. \\ com
}

Keywords: phyllite, cement modified, gradation, variance analysis theory, CBR

\begin{abstract}
This article selected the phyllite of the eastern Ankang section of the highway from Shiyan to Tianshui for raw materials,and made a series of experiments. The results showed that phyllite belongs to a kind of soft rock, low strength ,stability, and easy to collapse .This article is based on CBR test results,combined with analysis of variance theory analyzes the different cement dosage and coarse aggregate level matching phyllite packing effect of CBR.The results showed that the dosage of cement and coarse aggregate level matching phyllite CBR value effects are significant. When considering the economic and engineering characteristics,through the analysis,the choice with $3 \%$ the cement dosage and $55 \%$ the content of coarse aggregate of gradation combination is the best combination.
\end{abstract}

\section{Introduction}

Phyllite belongs to a kind of soft rock, low strength, stability, and easy to collapse, belong to the inferior in subgrade filling material,not easy to be directly used as a high-grade highway subgrade filling, and it needs to be modified after roadbed filling. The study of soft rock, the domestic and foreign scholars focused on the engineering properties of the filler, feasibility, modified strength before and after the change and the characteristics of immersion. Phyllite physical and mechanical properties were analyzed by T.R AMAMURTHY ${ }^{[1]}$ through the compression test. The cement modified phyllite based water filling road after wetting deformation is studied by Mao Xuesong ${ }^{[2]}$. From the above analysis shows that cement dosage and the level of pairing phyllite CBR value influence study is relatively small. In this paper, through the indoor test and variance theory analysis on the effects of phyllite CBR characteristics of different cement content and different coarse aggregate gradation level combination launched research and analysis, to determine which meet the mechanics characteristics and economic requirements of cement modified phyllite stuffing cement quantity and gradation level combination.

\section{The physical and mechanical properties of phyllite filler}

Phyllite rock uniaxial compressive strength test.The phyllite specimens were collected, according to the "standard of engineering rock mass test method" ${ }^{[3]}$ (GB/T50266-99), made the tetragonal shape rules, and divided into two groups, not full of water and full water respectively do uniaxial compressive strength test, the results obtained are shown in table 1.

Table 1 the uniaxial compressive strength test results

\begin{tabular}{|c|c|c|c|c|c|c|c|c|c|}
\hline \multirow{2}{*}{$\begin{array}{c}\text { group } \\
\text { number } \\
1 \\
1\end{array}$} & \multicolumn{3}{|c|}{$\begin{array}{c}\text { Not saturated rock } \\
\text { compressive strength } \\
\sigma_{c / \mathrm{MPa}}\end{array}$} & \multirow{2}{*}{$\begin{array}{r}\text { average } \\
27.2\end{array}$} & \multicolumn{3}{|c|}{$\begin{array}{c}\text { Saturated rock } \\
\text { compressive strength } \\
\qquad \sigma_{s c} / \mathrm{MPa}\end{array}$} & \multirow{2}{*}{$\begin{array}{c}\text { average } \\
\text { value } \\
13.5\end{array}$} & \multirow{2}{*}{$\begin{array}{l}\text { softening coefficient } \\
\qquad \begin{array}{c}\eta=\frac{\sigma_{\mathrm{c}}}{\sigma_{s c}} \\
0.5\end{array}\end{array}$} \\
\hline & 26.4 & 28.4 & 26.8 & & 12.1 & 14.9 & 13.4 & & \\
\hline 2 & 27.7 & 22.5 & 29.4 & 26.5 & 13.2 & 14.4 & 14.1 & 13.9 & 0.52 \\
\hline
\end{tabular}

Table 1 data showed that the scope of the uniaxial compressive strength of the original rock phyllite is $12 \sim 30 \mathrm{MPa}$. Therefore can be determined that the water stability of phyllite is bad, and it 
is the fragile soft rock.

The collapse of the phyllite packing features. Phyllite filler is made into varying sample size. And then put the test piece in the oven to bake until the weight is constant. And put in a dry container to weigh its weight. Then the sample was placed in the pot with water to submerge sample than $0.5 \mathrm{~cm}$, one day after soaking dried, weighed, a process called a cycle.The relationship between disintegration rate and the number of wet and dry cycles is shown in figure 1.

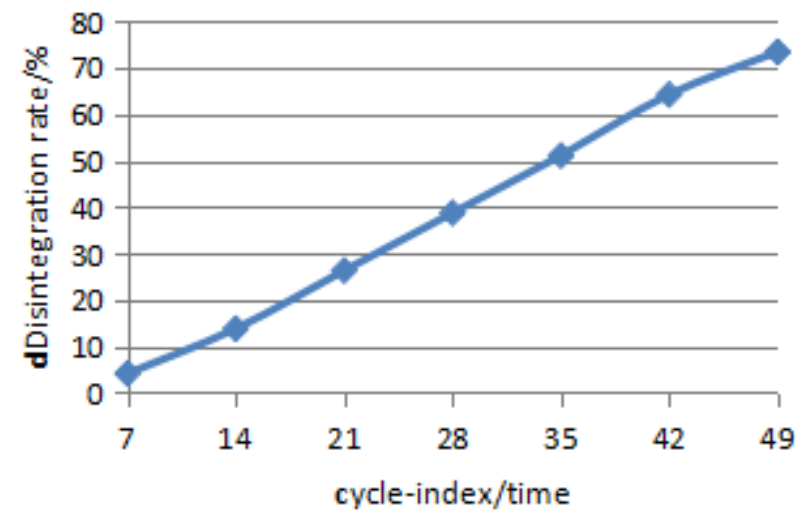

Figure 1 Weathered phyllite different cycles of wet and dry disintegration rate Figure 1s hows that the more the number of cycles, weathered phyllite disintegration rate of larger sa mple.Based on the analysis of experimental results, summarized that phyllite stuffing weathe ring resistance performance is poor, low strength, high degree of disintegration.

\section{Experimental Design}

Seen from the previous section, phyllite filler strength is poor. In order to improve the mechanical properties of phyllite filler, using cement improved roadbed. Table 2 choice of three different coarse aggregate gradation composition under the conditions of optimum moisture content. At the same time, the dosage of cement in each combination selected is $3 \%, 4 \%, 5 \%$,. $6 \%$.So the gradation composition and cement dosage level of number is 3 and 4, respectively. Under the best conditions formulated in different water content and cement specimen grading a test, every three specimens as a group, each experiment three times, a total of 36 experiments.

Table 2 Phyllite packing at all levels with combination of particle size(g)

\begin{tabular}{|l|c|c|c|c|c|c|c|c|c|c|c|c|c|c|}
\hline $\begin{array}{l}\text { stone } \\
\text { content/\% }\end{array}$ & 53 & 37.5 & 26.5 & 19 & 16 & 13.2 & 9.5 & 4.75 & 2.36 & 1.18 & 0.63 & 0.3 & 0.15 & \\
$\begin{array}{c}\text { screen size/m } \\
\mathrm{m}\end{array}$ & & & & & & & & & & & & & & \\
\hline $65 \%$ & 440 & 262 & 624 & 709 & 355 & 262 & 220 & 1028 & 709 & 355 & 495 & 112 & 149 & 280 \\
\hline $55 \%$ & 372 & 222 & 528 & 600 & 300 & 222 & 186 & 870 & 912 & 456 & 636 & 144 & 192 & 360 \\
\hline $45 \%$ & 304 & 182 & 432 & 491 & 245 & 182 & 152 & 712 & 1115 & 557 & 777 & 176 & 235 & 440 \\
\hline
\end{tabular}

\section{Analysis of test results}

The influence of different cement dosage and coarse aggregate on CBR value analysisAs can be seen from the chart, when the coarse aggregate content is certain, when increasing the cement content, improved CBR values phyllite rock filler also increases. CBR modified to give the maximum value is approximately 230\%.Description cement content phyllite improved CBR values have some effect. And when the cement content is constant, with the increase in coarse aggregate content after phyllite CBR value then decreases.Coarse aggregate of 55\% of the combination with respect to coarse aggregate of $65 \%$ and $45 \%$ of coarse aggregate is a better combination. 

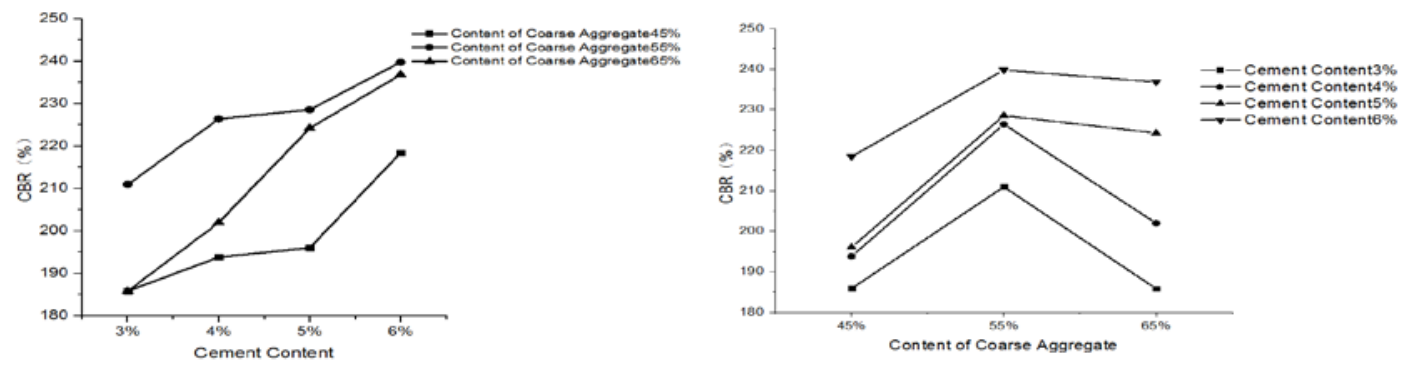

Figure 2 Cement and coarse aggregate content change on the influence of the CBR value

Effect of different gradations and different doses of cement CBR value of reusable two-way ANOVA Let factors a and b are respectively grading factors and cement content factor.In each of the different levels of combinations of conditions,each group performed three times independently repeated trials.So it can use "be repeated two-way ANOVA" of cement content and Grading on Cement Improved phyllite CBR value impact analysis of variance.The results of the analysis are shown in table 3.

Table 3 Can be repeated two factor analysis of variance

\begin{tabular}{|c|c|c|c|c|c|}
\hline $\begin{array}{c}\text { Differences } \\
\text { source }\end{array}$ & $\begin{array}{c}\text { Square } \\
\text { sum SS }\end{array}$ & $\begin{array}{c}\text { Degrees of } \\
\text { freedom }\end{array}$ & $\begin{array}{c}\text { Mean square } \\
\text { deviation }\end{array}$ & F-measure & Fcrit \\
\hline Factor a & 3685.5 & 2 & 1842.75 & 69.55228 & 3.402826 \\
\hline Factor b & 5432.75 & 3 & 1810.917 & 68.35077 & 3.008787 \\
\hline $\mathrm{a}^{\times} \mathrm{b}$ & 620.5 & 6 & 103.4167 & 3.903332 & 2.508189 \\
\hline Internal error & 635.867 & 24 & 26.49446 & & \\
\hline total variation & 10374.62 & 35 & 10374.62 & & \\
\hline
\end{tabular}

From the table 3 and variance analysis theory known the $\mathrm{F}$ test is significant.Indicates that the change of gradation and cement content and their interactions for a significant influence on the CBR value increased.Therefore, it is necessary to carry on the multiple comparison of the average measurement results of the gradation and cement content of two factors. The results are shown in the following table 4 、 5and 6 .

Table 4 Grading factor level for multiple comparisons

\begin{tabular}{|c|c|c|c|}
\hline factor level & average $\bar{x}_{i .}$ & $\bar{x}_{i .}-\mathrm{a}_{1}$ & $\bar{x}_{i .}-\mathrm{a}_{3}$ \\
\hline $\mathrm{a}_{2}$ & 220.25 & $24.75^{++}$ & $11.25^{++}$ \\
\hline $\mathrm{a}_{3}$ & 209 & $13.5^{++}$ & \\
\hline $\mathrm{a}_{1}$ & 195.5 & & \\
\hline Sort significant influence & \multicolumn{3}{|c|}{$\left.\mathrm{a}_{2} \gg \mathrm{a}_{3}\right\rangle \mathrm{a}_{1}$} \\
\hline
\end{tabular}

Table 5 Cement content factor level for multiple comparisons

\begin{tabular}{|c|c|c|c|c|}
\hline factor level & average $\bar{x}_{i .}$ & $\bar{x}_{i .}-\mathrm{b}_{1}$ & $\bar{x}_{i .}-\mathrm{b}_{2}$ & $\bar{x}_{i .}-\mathrm{b}_{3}$ \\
\hline $\mathrm{b}_{4}$ & 224.33 & $33.33^{++}$ & $20.33^{++}$ & $10.66^{++}$ \\
\hline $\mathrm{b}_{3}$ & 213.67 & $22.67^{++}$ & $9.67^{++}$ & \\
\hline $\mathrm{b}_{2}$ & 204 & $13^{++}$ & & \\
\hline $\mathrm{b}_{1}$ & 191 & & \\
\hline Sort significant influence & \multicolumn{3}{|c|}{$\left.\left.\left.\mathrm{b}_{4}\right\rangle \mathrm{b}_{3}\right\rangle \mathrm{b}_{2}\right\rangle \mathrm{b}_{1}$} \\
\hline
\end{tabular}


Table 6 Gradation and cement content interaction for multiple comparisons

\begin{tabular}{|c|c|c|c|c|c|c|c|c|c|c|c|c|}
\hline Interaction & average & $\mathrm{a}_{3} \mathrm{~b}_{1}$ & $\mathrm{a}_{1} \mathrm{~b}_{1}$ & $\mathrm{a}_{1} \mathrm{~b}_{2}$ & $\mathrm{a}_{1} \mathrm{~b}_{3}$ & $\mathrm{a}_{3} \mathrm{~b}_{2}$ & $\mathrm{a}_{2} \mathrm{~b}_{1}$ & $\mathrm{a}_{3} \mathrm{~b}_{3}$ & $\mathrm{a}_{3} \mathrm{~b}_{3}$ & $\mathrm{a}_{2} \mathrm{~b}_{2}$ & $\mathrm{a}_{2} \mathrm{~b}_{3}$ & $\mathrm{a}_{3} \mathrm{~b}_{4}$ \\
\hline $\mathrm{a}_{2} \mathrm{~b}_{4}$ & 233 & $49^{++}$ & $49^{++}$ & $43^{++}$ & $35^{++}$ & $31^{++}$ & $28^{++}$ & $23^{++}$ & $13^{++}$ & $13^{++}$ & $10^{+}$ & 3 \\
\hline $\mathrm{a}_{3} \mathrm{~b}_{4}$ & 230 & $46^{++}$ & $40^{++}$ & $40^{++}$ & $32^{++}$ & $28^{++}$ & $25^{++}$ & $20^{++}$ & $10^{+}$ & $10^{+}$ & 7 & \\
\hline $\mathrm{a}_{2} \mathrm{~b}_{3}$ & 223 & $39^{++}$ & $39^{++}$ & $33^{++}$ & $25^{++}$ & $21^{++}$ & $18^{++}$ & $13^{++}$ & 3 & 3 & & \\
\hline $\mathrm{a}_{2} \mathrm{~b}_{2}$ & 220 & $36^{++}$ & $36^{++}$ & $30^{++}$ & $22^{++}$ & $18^{++}$ & $15^{++}$ & $10^{+}$ & & & & \\
\hline $\mathrm{a}_{3} \mathrm{~b}_{3}$ & 220 & $36^{++}$ & $36^{++}$ & $30^{++}$ & $22^{++}$ & $18^{++}$ & $15^{++}$ & $10^{+}$ & & & & \\
\hline $\mathrm{a}_{1} \mathrm{~b}_{4}$ & 210 & $26^{++}$ & $26^{++}$ & $20^{++}$ & $12^{++}$ & 8 & 5 & & & & & \\
\hline $\mathrm{a}_{2} \mathrm{~b}_{1}$ & 205 & $21^{++}$ & $21^{++}$ & $15^{++}$ & 7 & 3 & & & & & & \\
\hline $\mathrm{a}_{3} \mathrm{~b}_{2}$ & 202 & $18^{++}$ & $18^{++}$ & 12 & 4 & & & & & & & \\
\hline $\mathrm{a}_{1} \mathrm{~b}_{3}$ & 198 & $14^{++}$ & 14 & 8 & & & & & & & & \\
\hline $\mathrm{a}_{1} \mathrm{~b}_{2}$ & 190 & 6 & 6 & & & & & & & & & \\
\hline $\mathrm{a}_{1} \mathrm{~b}_{1}$ & 184 & & & & & & & & & & & \\
\hline $\mathrm{a}_{3} \mathrm{~b}_{1}$ & 184 & & & & & & & & & & & \\
\hline
\end{tabular}

From the table 4,it indicated that at different levels of paired cement modified phyllite CBR values increasing and influencing the worst is coarse aggregate content of $45 \%$, followed by $65 \%$,and the best is $55 \%$.

From the table5, it explained that when the cement content is 6\%,the effect of cement content on the increase of CBR value is the greatest. Followed by $5 \%$ of cement dosage level, and then is $4 \%$ and $3 \%$ of cement dosage level.

From the table 6,it explained that the content of coarse aggregate and cement content interaction were $55 \%$ and $6 \%$, the impact effect on the improvement of CBR value increased most significantly.It is followed by $65 \%$ and $6 \%$ of the combinations and again it was $55 \%$ and $5 \%$ of the combinations.

Through the above analysis showed that, when taking into account the need to meet the requirements of economic and engineering, in the cement dosage is $3 \%$, compared to in coarse aggregate content of $45 \%$ and $65 \%$, coarse aggregate content is $55 \%$ of CBR value increase impact is the biggest. Therefore, it is most satisfied to the engineering and economic requirements of the best cement amount and the gradation composition.

\section{Summary}

Through trial and may be repeated two-way ANOVA analysis showed significant cement content and coarse particle content all have an influence on phyllite CBR.With the increase of cement content and coarse particle content, CBR value increased also.

\section{Acknowledgments}

This work was financially supported by the Natural Science Foundation of China(51378072).

\section{References}

[1] T.Ramamurthy.Engineering properties of phyllite[J].Yangtze River.1994,25(12):48-52.

[2] Mao Xuesong,ZZheng Xiaozhong,Ma Biao,eg.Weathered phyllite filling roadbed of wetting deformation field test analysis[J].Rock and Soil Mechanics,2011,8: 2300-2303.

[3] The original electric power industry ministry of the People's Republic of China.Gb/T 50266-99,The standard of the engineering rock mass test method [S].China standard publishing house,1999.

[4] RIOH.JTJ E40-2007,Test method of soils for highway engineering [S].China Communications Press,2007. 